\title{
Clear cell neuroendocrine tumor in the gallbladder diagnosed as a benign polyp preoperatively: a case report
}

\author{
Ryusuke Sumiya', Atsushi Shimizu", Takeshi Nagai , Hayato Ono', Keigo Kumazawa', Daisuke Endo',
} Takashi Oide ${ }^{2}$ and Nobuyoshi Aoyanagi ${ }^{1}$

\begin{abstract}
Background: Gallbladder neuroendocrine neoplasm is a rare disease that is divided into neuroendocrine tumors (NETs) and neuroendocrine carcinomas (NECs). Clear cell NETs of the gallbladder are extremely rare. We report the case of a patient with polypoid clear cell NET G1 of the gallbladder who underwent laparoscopic cholecystectomy.

Case presentation: A 10-mm pedunculated polyp in the gallbladder neck was detected on a follow-up abdominal ultrasound in a 60-year-old man with chronic hepatitis and hepatitis B without medication. Six months later, an abdominal ultrasound revealed that the tumor had enlarged to $12 \mathrm{~mm}$ in size. He was asymptomatic and had no abnormalities in other laboratory examinations, including the tumor markers, carcinoembryonic antigen and CA199. Abdominal ultrasound showed a 12-mm polyp in the neck of the gallbladder with perfusion and focal thickening of the gallbladder wall. A gallbladder stone was also seen in the fundus. An enhanced computed tomography scan and magnetic resonance imaging revealed a polypoid lesion and gallbladder stone located at the neck of the gallbladder and the fundus, respectively. Malignancy could not be excluded, and hence, a laparoscopic cholecystectomy was performed. Pathologically, a pedunculated polyp $(14 \times 11 \times 15 \mathrm{~mm})$ was observed in the neck of the gallbladder, and the polypoid lesion comprised nests or trabecular growths of clear NET cells in the lamina propria (ENETS: T1NOMO; AJCC: T1aNOMO). Immunohistochemical staining with synaptophysin, chromogranin A, and CD56 was confined to the tumor. The pathological diagnosis was clear cell NET G1 of the gallbladder. Although clear cell NET is often described as a distinct manifestation of von Hippel-Lindau disease (VHL), the patient had no past medical or family history of VHL. Until his one-and-a-half-year follow-up, the patient was doing well and without any signs of recurrence.
\end{abstract}

Conclusion: We report an extremely rare case of gallbladder clear cell NET G1. When NET G1 is incidentally identified in a gallbladder surgical specimen, clinical information and pathological findings should be considered as references.

Keywords: NET, Neuroendocrine neoplasm, Gallbladder, Endoscopic surgery, Case report

\footnotetext{
* Correspondence: atsushis-tky@umin.ac.jp

'Department of Surgery, Kohnodai Hospital, National Center for Global Health and Medicine, 1-7-1 Kohnodai, Ichikawa-shi, Chiba 272-8156, Japan

Full list of author information is available at the end of the article
}

(c) The Author(s). 2021 Open Access This article is licensed under a Creative Commons Attribution 4.0 International License, which permits use, sharing, adaptation, distribution and reproduction in any medium or format, as long as you give appropriate credit to the original author(s) and the source, provide a link to the Creative Commons licence, and indicate if changes were made. The images or other third party material in this article are included in the article's Creative Commons licence, unless indicated otherwise in a credit line to the material. If material is not included in the article's Creative Commons licence and your intended use is not permitted by statutory regulation or exceeds the permitted use, you will need to obtain permission directly from the copyright holder. To view a copy of this licence, visit http://creativecommons.org/licenses/by/4.0/. The Creative Commons Public Domain Dedication waiver (http://creativecommons.org/publicdomain/zero/1.0/) applies to the data made available in this article, unless otherwise stated in a credit line to the data. 


\section{Background}

Neuroendocrine neoplasm (NEN), particularly gallbladder NEN, is a rare condition [1]. The World Health Organization 2018 classification divides NEN into two families. The well-differentiated family pertains to neuroendocrine tumor (NET), and the poorly differentiated family includes neuroendocrine carcinoma (NEC). NET is usually graded in three tiers, namely, G1, G2, and G3, which correspond to low-grade, intermediate-grade, and high-grade, respectively [2]. Among them, clear cell NET of the gallbladder is rare, and previous reports have revealed that several cases with clear cell NET are associated with von Hippel-Lindau (VHL) disease [3]. Although a patient with NET G1 has a relatively good prognosis, it is usually difficult to estimate the histological grade and to diagnose a gallbladder NEN during preoperative examination. Several cases of gallbladder NEN patients who underwent cholecystectomy because they were preoperatively diagnosed with a benign tumor have been reported [1]. Herein, we report a patient with polypoid clear cell NET G1 of the gallbladder who underwent laparoscopic cholecystectomy.

\section{Case presentation}

A $10-\mathrm{mm}$ pedunculated polyp in the gallbladder neck was detected on a follow-up abdominal ultrasound in a 60-year-old man with chronic hepatitis and hepatitis B without medication. A benign tumor or low-grade malignancy was suspected, and he initially did not wish to undergo surgical resection. Six months later, an abdominal ultrasound showed an increase in the polyp to 12 $\mathrm{mm}$ at the neck of the gallbladder with point-like perfusion, focal thickening of the gallbladder wall, and a gallbladder stone at the fundus (Fig. 1). Enhanced computed tomography (CT) scan (Fig. 2) and magnetic resonance imaging (MRI) (Fig. 3) revealed a polypoid lesion at the neck of the gallbladder, a distended gallbladder with a thickened and enhanced wall, and a gallbladder stone at the fundus. He was asymptomatic, and laboratory examinations revealed that the patient had a normal liver function and coagulation with hepatitis B virus DNA level of $3.2 \log \mathrm{IU} / \mathrm{ml}$; positive and negative serologic markers for hepatitis B envelope antibody and envelope antigen, respectively, and the tumor marker levels were within normal ranges [carcinoembryonic antigen, CEA $(1.8 \mathrm{U} / \mathrm{ml}$; normal range $<5.0 \mathrm{U} / \mathrm{ml})$ and CA19-9 $(9.9 \mathrm{U} /$ $\mathrm{ml}$; normal range $<37 \mathrm{U} / \mathrm{ml}$ )]. Although the patient was diagnosed with a benign gallbladder polyp, malignancy could not be completely excluded. Therefore, a laparoscopic cholecystectomy was performed. Intraoperatively, only a slight thickening of the gallbladder wall was detected. Macroscopically, there was a pedunculated yellowish polyp $(14 \times 11 \times 15 \mathrm{~mm})$ at the neck of the gallbladder. The gallbladder wall was thickened, and the
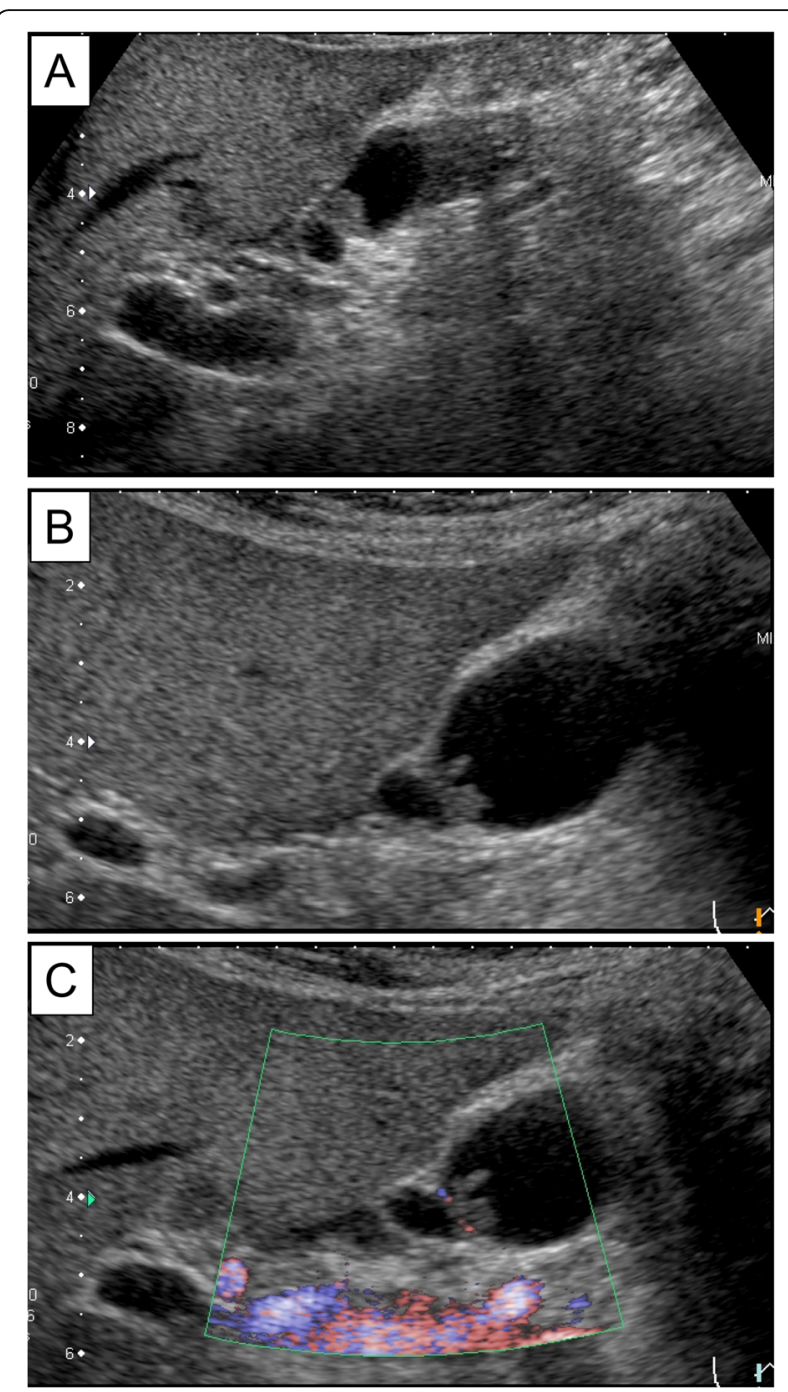

Fig. 1 Representative images of the abdominal ultrasound. a A 10$\mathrm{mm}$ polyp in the neck of the gallbladder was seen 6 months ago. $\mathbf{b} \mathrm{A}$ $12-\mathrm{mm}$ polyp in the neck of the gallbladder with perfusion and focal thickening of the gallbladder wall in the fundus. c Color Doppler imaging of the pedunculated polyp in the neck of the gallbladder

Rokitansky-Aschoff sinus (RAS) was clustered at the wall (Fig. 4a).

Histopathological examination revealed solid or trabecular nests of tumor cells in the polypoid lesion. These tumor cells were uniformly monotonous with a small round nucleus and multivacuolated clear cytoplasm (Fig. 4b), and the cytoplasm was negative for periodic acid-Schiff reaction. Necrosis and mitosis were not observed. The surface of the polyp was composed of a biliary epithelium without atypia. The neoplastic lesion was restricted to the lamina propria, and neither vascular nor lymphatic invasion was present (ENETS: T1NOM0; AJCC: T1aNOM0). Chronic cholecystitis with RAS was observed in the surrounding gallbladder tissue. Immunohistochemically, the tumor cells were positive for synaptophysin, 

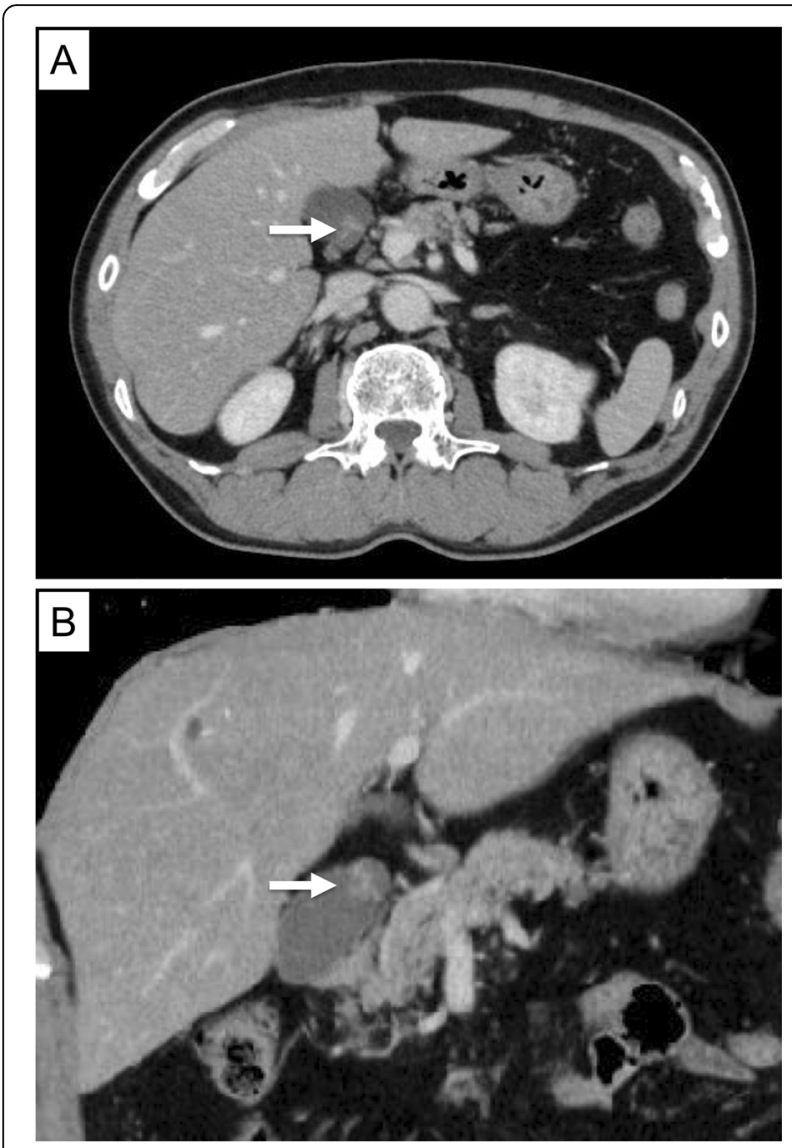

Fig. 2 Representative images from the contrast-enhanced $\subset T$ scan with portal venous phase. Arrow shows a pedunculated polypoid lesion in the neck of the gallbladder (a: axial image, $\mathbf{b}$ : coronal image)

chromogranin $\mathrm{A}$, and CD56, indicating neuroendocrine differentiation (Fig. 4c, d). The expression of Ki-67 showed a labeling index of $<2 \%$. Hence, the tumor was diagnosed as clear cell NET G1 of the gallbladder. No additional treatment was administered because R0 resection was performed using cholecystectomy, and there was no evidence

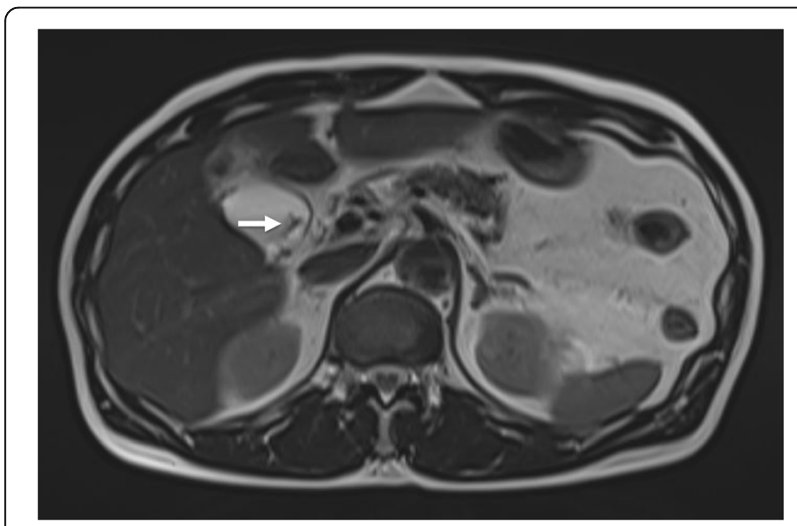

Fig. 3 Representative image from the T2 axial MRI. A pedunculated polypoid lesion was observed in the neck of the gallbladder of invasion or metastasis to other organs. Although clear cell NET may appear as a part of VHL disease, the patient had no clinical findings and family history of VHL. The patient is doing well without any signs of recurrence until the one-and-a-half-year follow-up period.

\section{Discussion and conclusion}

NEN is a rare disease, and its prevalence is approximately 5.25 per 100,000 [1]. NEN has been described in the gastrointestinal tract, lungs, trachea, and thyroid. However, NEN rarely occurs in the gallbladder, accounting for only $0.04-0.5 \%$ of all NEN cases $[4,5]$. In particular, gallbladder NET with clear cell is rare, with only four reported cases (Table 1) [3, 6-8]. Since little is known about the clinicopathological features of clear cell NEN in the gallbladder, we present this rare case of gallbladder NEN with clear cell in this report.

The mechanisms of occurrence of gallbladder NEN have not been explained because the normal gallbladder mucosa has no neuroendocrine cell. Previous research reported that the proportion of neuroendocrine cells increases during chronic inflammation in the affected metaplastic epithelium, which may result in NEN. This explains why patients with gallbladder NEN often have gallbladder stones and cholecystitis [9]. A previous study revealed that $65 \%$ of gallbladder NETs frequently arise from the neck of the gallbladder, while $35 \%$ occur in the body or fundus. Although $61.5 \%$ of gallbladder NETs in the neck are pedunculated, $38.5 \%$ of gallbladder NETs in the neck and all gallbladder NETs in the body and fundus are not pedunculated [10]. Almost all gallbladder NEN patients are asymptomatic, and the proportion of hormone-producing gallbladder NENs is unknown because of the small number of reported cases [11]. Regarding clear cell gallbladder NET, most cases were in the neck of the gallbladder and pedunculated, and all cases were surgically resected by laparoscopic cholecystectomy. Only one case underwent a radical second resection and lymphadenectomy because the patient had a cystic lymph node metastasis. However, since cystic lymph node metastases were absent in the other cases and present case, radical resection was not necessary.

Due to the lack of specific findings on the CT scan or MRI, it is difficult to diagnose gallbladder NEN preoperatively. Gallbladder NEN is often misdiagnosed as a benign tumor, i.e., cholesterol polyp or adenoma prior to surgery. If the diagnosis of gallbladder NEN was made preoperatively, we should have considered operative methods such as local excision, radical resection, and lymphadenectomy. Previous research recommends that local excision without lymphadenectomy should be carried out for NET G1 tumors less than $2 \mathrm{~cm}$ in the stomach, duodenum, appendix, and rectum. Lymphadenectomy is recommended for other gastroenteropancreatic NENs in the jejunum, ileum, 


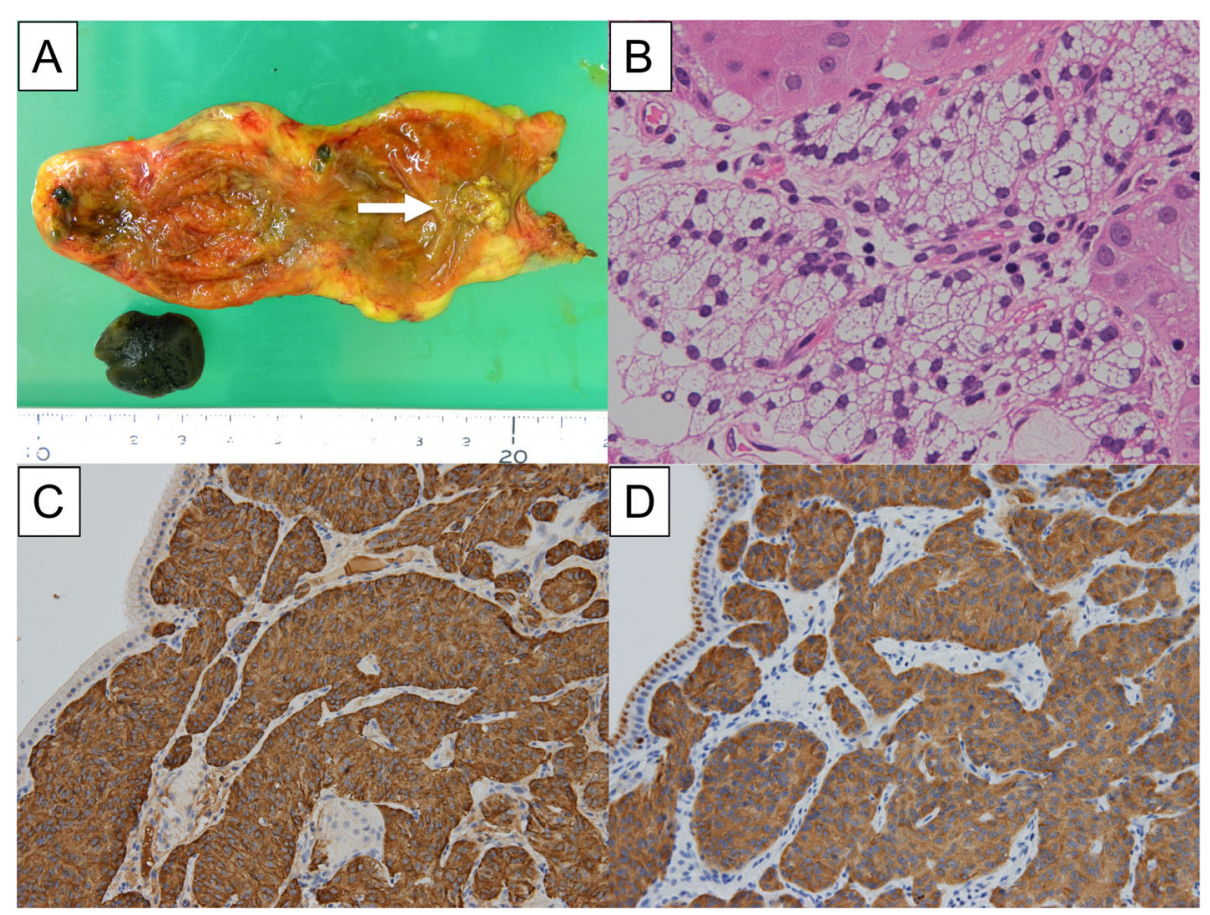

Fig. 4 Representative images with pathological findings. a A pedunculated polyp $(14 \times 11 \times 15 \mathrm{~mm})$ was observed in the neck of the gallbladder (arrow), the gallbladder wall was thickened, and Rokitansky-Aschoff sinus (RAS) could be observed clustered in the wall. b The polypoid lesion comprised solid or trabecular nests of NET cells. These tumor cells had multivacuolated clear cytoplasm (hematoxylin and eosin staining, $\times 40$ magnification). Immunohistochemically, the tumor cells were positive for synaptophysin (c) and chromogranin A (d)

colon, and pancreas $[9,11]$. Although the risk of metastasis depends on the tumor size in several gastroenteropancreatic NENs, the risk factors for metastasis of gallbladder NEN have not been clarified because only a small number of cases have been reported [11]. Previous NET research reported that the frequency of metastases was two of seven cases $(28.6 \%)$ for tumors less than $1 \mathrm{~cm}$, while all five cases with tumors measuring $3 \mathrm{~cm}$ or more had metastases. This research indicated that tumor size is a possible risk factor of metastases for gallbladder NEN [12]. Frequent sites of metastatic lesions were the liver (91.7\%), lungs (33.3\%), lymph nodes (33.3\%), bone (25\%), and adrenal glands (25\%) [8-12]. Only one case of gallbladder NET G1 less than $1 \mathrm{~cm}$ had lymph node metastasis [8]. MRI is a useful tool in staging gallbladder tumors, and previous research revealed the high sensitivity rates for lymph node invasion on MRI (92\%) [13]. Therefore, we elucidated the tumor size and lymph node metastasis on MRI preoperatively. Postoperatively, if NET G1 was incidentally identified in the gallbladder of a surgical specimen, reports suggested that a detailed pathological examination of the cystic duct node should be performed [8]. If lymph node metastasis is positive, a radical second resection with regional lymphadenectomy should be

Table 1 Reported cases of clear cell NET G1 in the gallbladder

\begin{tabular}{|c|c|c|c|c|c|c|c|c|c|}
\hline No. & Age & Sex & Location & Form & $\begin{array}{l}\text { Preoperative } \\
\text { diagnosis }\end{array}$ & $\begin{array}{l}\text { Size } \\
(\mathrm{mm})\end{array}$ & Operation & $\begin{array}{l}\text { Invasion } \\
\text { depth }\end{array}$ & Metastasis \\
\hline $\begin{array}{l}1 \\
{[3]}\end{array}$ & 38 & $M$ & $\begin{array}{l}\text { Neck of } \\
\text { gallbladder }\end{array}$ & Pedunculated & $\begin{array}{l}\text { Metastasis of } \\
\text { renal cancer }\end{array}$ & 14 & Lap cholecystectomy & $\begin{array}{l}\text { Full } \\
\text { thickness }\end{array}$ & None \\
\hline $\begin{array}{l}2 \\
{[6]}\end{array}$ & 64 & $M$ & $\begin{array}{l}\text { Neck of } \\
\text { gallbladder }\end{array}$ & Pedunculated & $\begin{array}{l}\text { Cholesterol } \\
\text { polyp }\end{array}$ & 8 & Lap cholecystectomy & $\begin{array}{l}\text { Subserosal } \\
\text { layer }\end{array}$ & None \\
\hline $\begin{array}{l}3 \\
{[7]}\end{array}$ & 71 & $M$ & $\begin{array}{l}\text { Fundus of } \\
\text { gallbladder }\end{array}$ & Pedunculated & Polyp & 9 & Lap cholecystectomy & $\begin{array}{l}\text { Lamina } \\
\text { propria }\end{array}$ & None \\
\hline $\begin{array}{l}4 \\
{[8]}\end{array}$ & 65 & $M$ & $\begin{array}{l}\text { Neck of } \\
\text { gallbladder }\end{array}$ & $\begin{array}{l}\text { Non- } \\
\text { pedunculated }\end{array}$ & RAS & 8 & $\begin{array}{l}\text { Lap cholecystectomy + radical second } \\
\text { resection + lymphadenectomy }\end{array}$ & $\begin{array}{l}\text { Muscular } \\
\text { layer }\end{array}$ & $\begin{array}{l}\text { Lymph } \\
\text { node }\end{array}$ \\
\hline $5^{a}$ & 70 & $M$ & $\begin{array}{l}\text { Neck of } \\
\text { gallbladder }\end{array}$ & Pedunculated & Polyp & 15 & Lap cholecystectomy & $\begin{array}{l}\text { Lamina } \\
\text { propria }\end{array}$ & None \\
\hline
\end{tabular}


considered. In this case, a small tumor size $(1.5 \mathrm{~cm})$ and histological type (NET G1) were associated with a good prognosis without metastasis. In addition, preoperative MRI showed no evidence of lymph node metastasis.

Generally, the cytoplasm of NEN cells is eosinophilic to amphophilic. However, few cases have a clear cytoplasm, which are described as clear cell NEN. A previous report showed that clear cell NEN of the pancreas is a clinical presentation of VHL [14]. Only four cases of clear cell gallbladder NEN have been described in previous literature, and one case was associated with VHL [8]. In the other three cases, i.e., non-VHL-related cases, prior reports indicated that chronic cholecystitis and gallbladder stones may be associated with clear cell NET G1, likewise the pathogenesis of canonical gallbladder NEN [6-8]. This patient had no clinical feature and family history of VHL disease.

In conclusion, while gallbladder NEN is rare and clear cell NET has been reported as a clinical presentation of VHL, this case of gallbladder clear cell NET G1 is particularly notable due to the absence of VHL. Further, we showed that G1 NETs less than $2 \mathrm{~cm}$ without lymph nodes and distant metastases can be treated with laparoscopic cholecystectomy and local excision. However, further research is necessary to evaluate imaging findings prior to surgery, to determine the surgical procedure, and to identify the potential prognostic factors. When NET G1 is incidentally identified in a gallbladder surgical specimen, clinical information and pathological findings should be considered as references.

\section{Abbreviations}

NEN: Neuroendocrine neoplasm; NET: Neuroendocrine tumor; NEC: Neuroendocrine carcinoma; VHL: von Hippel-Lindau; CT: Computed tomography; MRI: Magnetic resonance imaging

\section{Acknowledgements}

This work was supported in part by Grants-in-Aid for Research from the National Center for Global Health and Medicine (20A 3001).

We would like to thank Editage (www.editage.com) for English language editing.

\section{Authors' contributions}

$\mathrm{RS}$ and $\mathrm{AS}$ wrote the paper. TN, HO, KK, DE, TO, and NA contributed to the paper design and coordination. All authors have read and approved the manuscript.

\section{Funding}

None

\section{Availability of data and materials}

Not applicable.

\section{Ethics approval and consent to participate}

Written consent was obtained from the patient. As this is a case report, approval from the institutional review board was not needed.

\section{Consent for publication}

Written informed consent was obtained from the patient for the publication of this report and any accompanying images.

\section{Competing interests}

The authors declare that they have no competing interests.

\section{Author details}

${ }^{1}$ Department of Surgery, Kohnodai Hospital, National Center for Global Health and Medicine, 1-7-1 Kohnodai, Ichikawa-shi, Chiba 272-8156, Japan.

${ }^{2}$ Department of Pathology and Laboratory Medicine, Kohnodai Hospital,

National Center for Global Health and Medicine, Ichikawa, Japan.

Received: 1 November 2020 Accepted: 2 December 2020

Published online: 02 January 2021

\section{References}

1. Liu W, Chen W, Chen J, Hong T, Li B, Qu Q, et al. Neuroendocrine carcinoma of gallbladder: a case series and literature review. Eur J Med Res. 2019;24:8.

2. Rindi G, Klimstra DS, Abedi-Ardekani B, Asa SL, Bosman FT, Brambilla E, et al. A common classification framework for neuroendocrine neoplasms: an international agency for research on cancer (IARC) and world health organization (WHO) expert consensus proposal. Mod Pathol. 2018;31:1770-86.

3. Sinkre P, Murakata L, Rabin L, Hoang MP, Albores-Saavedra J. Clear cell carcinoid tumor of the gallbladder: another distinctive manifestation of von Hippel-Lindau disease. Am J Surg Pathol. 2001;25:1334-9.

4. Hough DM, Stephens DH, Johnson CD, Binkovitz LA. Pancreatic lesions in von Hippel-Lindau disease: prevalence, clinical significance, and CT findings. AJR Am J Roentgenol. 1994;162:1091-4.

5. Nishigami T, Yamada M, Nakasho K, Yamamura M, Satomi M, Uematsu K, et al. Carcinoid tumor of the gall bladder. Intern Med. 1996;35:953-6.

6. Konishi E, Nakashima Y, Smyrk TC, Masuda S. Clear cell carcinoid tumor of the gallbladder. A case without von Hippel-Lindau disease. Arch Pathol Lab Med. 2003;127:745-7.

7. Ishida M, Shiomi H, Naka S, Tani T, Okabe H. Clear cell neuroendocrine tumor $\mathrm{G} 1$ of the gallbladder without von Hippel-Lindau disease. Oncol Lett. 2012;4:1174-6.

8. Hirose $Y$, Sakata J, Endo K, Takahashi M, Saito R, Imano H, et al. A 0.8-cm clear cell neuroendocrine tumor $\mathrm{G} 1$ of the gallbladder with lymph node metastasis: a case report. World J Surg Oncol. 2018;16:150.

9. Eltawil K, Gustafsson B, Kidd M, Modlin I. Neuroendocrine tumors of the gallbladder: an evaluation and reassessment of management strategy. J Clin Gastroenterol. 2010;44:687-95.

10. Oku T, Ono K, Nagamachi Y, Misu K, Senmaru N, Fujita M, et al. Pedunculated carcinoid tumor of the gallbladder - analysis of the relationship between location and morphology in carcinoid tumor of the gallbladder. Nihon Syokakibyo Gakkai Zasshi. 2008;105:397-403.

11. Naito S, Naito M, Yamamoto N, Kume T, Hosino S, Kinjyo Y, et al. Polypoid gallbladder neuroendocrine tumor diagnosed as benign polyp before surgery: a case report. Mol Clin Oncol. 2020;12:225-9.

12. Yokoyama Y, Fujioka S, Kato K, Tomono H, Yoshida K, Nimura Y. Primary carcinoid tumor of the gallbladder: resection of a case metastasizing to the liver and analysis of outcomes. Hepatogastroenterology. 2000;47:135-9.

13. Monier A, Saloum N, Szmigielski W, Alrashid A, Napaki SME. Neuroendocrine tumor of the gallbladder. Pol J Radiol. 2015;80:228-31.

14. Hoang M, Hruban R, Albores-Saavedra J. Clear cell endocrine pancreatic tumor mimicking renal cell carcinoma: a distinctive neoplasm of von Hippel-Lindau disease. Am J Surg Pathol. 2001;25:602-9.

\section{Publisher's Note}

Springer Nature remains neutral with regard to jurisdictional claims in published maps and institutional affiliations. 